\title{
A IMPORTÂNCIA DODIAGNÓSTICO PRECOCE DE CARDIOPATIA CONGÊNITA: RELATO DE CASO
}

Pôster

Autores deste trabalho:

RAFAELA OLIVEIRA TAVARES: Hospital Infantil Cândido Fontoura

Ingrid Lacerda Pessoa: Hospital Infantil Cândido Fontoura

Pedro Teles de Mendonça Neto: Hospital Infantil Cândido Fontoura

Mariana Aparecida Brunossi Moura Proença: Hospital Infantil Cândido Fontoura

Maryana Beltrão de Carvalho: Hospital Infantil Cândido Fontoura

João Pedro de Figueiredo Jordão Furtado de Mendonça: Hospital Infantil Cândido Fontoura

Lineke Gonçalves Dias: Hospital Infantil Cândido Fontoura

Raquel Fontana: Hospital Infantil Cândido Fontoura

Área do Trabalho: Pediatria

Data da submissão: $30 / 07 / 2018$ às 21:06

\section{Justificativa}

As cardiopatias congênitas são frequentes e responsáveis pela metade da mortalidade por malformações na infância. Cerca de 1 a 2 de cada 1000 recémnascidos vivos apresentam cardiopatia congênita crítica. Em torno de 30\% destes recém-nascidos recebem alta sem o diagnóstico, e evoluem para choque, hipóxia ou óbito precoce, antes de receber tratamento adequado.

\section{Objetivo(s)}

O presente estudo tem o objetivo de relatar o caso clínico de uma paciente com tetralogia de Fallot associada a atresia pulmonar.

\section{Método(s)}

Não se aplica

\section{Resultado(s)}

M.P.T., 6 meses, feminino, natural da Bahia. Veio à São Paulo para investigação de cianose desde o nascimento com piora ao choro. Refere que não recebeu diagnóstico para tal sinal, no local onde nasceu. Ao exame físico: cianose 4+/4, intensificada com o choro; bulhas rítmicas normofonéticas, com sopro sistólico 1+/6 em região infraclavicular e dorsal; Precórdio adinâmico; Saturação de oxigênio entre 60 - 70\% em cateter de 02. Baqueteamento digital. O eletrocardiograma mostrava sobrecarga ventricular direita e hipertrofia atrial à direita. O ecocardiograma com presença de atresia pulmonar; tetralogia de Fallot, colaterais sistêmicos pulmonares e forame oval pérvio. Radiografia de tórax com hipofluxo pulmonar, coração em bota; índice cardiotorácico de 1,18. Paciente encaminhada à cirurgia, porém foi a óbito durante a mesma. 


\section{$4^{\circ}$ Congresso Internacional Sagbaró \\ 13 a 15 de \\ 13 a 15 de 2018}

Hotel Maksoud Plaza
Alameda Campinas, 150
Säo Paulo- Brosil

\section{Conclusão (ões)}

A sociedade brasileira de pediatria indica a realização do teste do coraçãozinho, em todos os neonatos aparentemente saudáveis, com a idade gestacional maior que 34 semanas, antes que recebam a alta hospitalar. Caso o resultado esteja alterado, o teste deverá ser repetido após 1 hora. Se confirmar anormalidade, deverá ser realizado um ecocardiograma dentro de 24 horas. O teste do coraçãozinho é um teste que possui alta sensibilidade e especificidade, não invasivo e de fácil aplicação, possibilitando o diagnóstico e tratamento precoce das cardiopatias congênitas. 